\title{
ANALISIS DINDING DIAFRAGMA DENGAN PENGHILANGAN RINGSLAB SECARA EFEKTIF PADA KONSTRUKSI BASEMENT
}

\author{
Timotius Hazel $^{1}$, Sunarjo Leman ${ }^{2}$, dan Ali Iskandar ${ }^{3}$ \\ ${ }^{1}$ Program Studi Sarjana Teknik Sipil, Universitas Tarumanagara, Jl. Letjen S. Parman No.1 Jakarta \\ Email: timotius_hazel@yahoo.com \\ ${ }^{2}$ Program Studi Sarjana Teknik Sipil, Universitas Tarumanagara, Jl. Letjen S. Parman No.1 Jakarta \\ Email: sunarjo@ft.untar.ac.id \\ ${ }^{3}$ Program Studi Sarjana Teknik Sipil, Universitas Tarumanagara, Jl. Letjen S. Parman No.1 Jakarta \\ Email: ali.iskandar1999@gmail.com
}

\begin{abstract}
ABSTRAK
Basement merupakan struktur bawah tanah yang dapat berfungsi sebagai tempat parkir dan ruangan. Dalam pengerjaannya, dibutuhkan galian dalam pada tanah yang dapat menyebabkan perubahan tegangan, regangan serta deformasi pada tanah. Pada analisis ini akan mengambil studi kasus galian dalam pada proyek pembangunan basement di kawasan bendungan hilir. Metode konstruksi yang digunakan adalah metode top down. Dinding diafragma dengan tebal 1 meter dan panjang 55 meter dikonstruksikan pada galian. Jumlah basement yang direncanakan pada pembangunan ini ada 7 lantai basement. Untuk mempercepat proses penggalian, maka pengerjaan slab yang berfungsi sebagai strut tidak dilakukan pada tiap selesai penggalian, tetapi ada lantai yang pengerjaan slabnya dihilangkan sementara, yang dikerjakan pada akhir penggalian sehingga proses galian akan lebih cepat diselesaikan. Oleh karena itu, analisis ini akan berfokus pada perhitungan deformasi dinding diafragma, momen yang terjadi serta gaya-gaya pada slab/strut. Analisis ini akan dibantu dengan program elemen hingga (2D) dengan pemodelan kegagalan tanah mohr-colomb dan dicoba pada kondisi drained dan undrained.
\end{abstract}

Kata kunci: basement, galian dalam, dinding diafragma, mohr-coulomb, program elemen hingga (2D)

\section{PENDAHULUAN}

\section{Latar Belakang}

Pada zaman sekarang ini, pembangunan di kota-kota besar seperti Jakarta sudah mengalami kemajuan yang sangat pesat dibanding zaman dahulu. Pembangunan di Jakarta yang meningkat dikarenakan jumlah penduduk yang meningkat secara signifikan serta banyaknya lapangan pekerja yang tersedia di Jakarta sehingga banyak masyarakat dari luar Jakarta yang datang. Dikarenakan besarnya jumlah penduduk di Jakarta tetapi jumlah lahan di Jakarta yang tidak bertambah, maka banyak gedung-gedung tinggi di Jakarta karena adanya keterbatasan lahan.

Gedung-gedung saat ini tidak hanya menjulang keatas tetapi juga kebawah yang pada umumnya digunakan sebagai lahan parkir karena kurangnya lahan yang tersedia di perkotaan. Dan basement (struktur bawah tanah) merupakan pilihan yang tepat untuk memenuhi kebutuhan lahan parkir tersebut.

Pembangunan basement sendiri memerlukan perencanaan desain dan tahapan pelaksanaan konstruksi yang akurat serta tepat. Dikarenakan basement merupakan bagian paling bawah dari sebuah gedung bertingkat, maka metode pelaksanaan konstruksi yang diterapkan harus tepat agar dapat mempercepat pembangunan proyek.

Pada penelitian ini dilakukan peninjauan pada salah satu proyek di kawasan Bendungan Hilir yang direncanakan memiliki basement 7 lantai hingga kedalaman 27 meter. Serta kawasan disekitar proyek adalah kawasan padat penduduk sehingga pelaksanaan harus dilakukan secara efisien dan efektif agar tidak menganggu penduduk sekitar. Oleh karena itu penulis akan menganalisis serta membahas letak ring slab yang dapat dihilangkan sementara dalam galian dalam proyek ini. Agar proses penggalian tanah dan pembuatan basement dapat lebih cepat selesai serta juga dapat dilakukan pengerjaan struktur atas.

\section{Batasan Masalah}

Adapun batasan masalah yang akan dibahas adalah:

1. Lokasi dari studi kasus yang diteliti merupakan proyek gedung bertingkat di kawasan Bendungan Hilir.

2. Melakukan analisa data tanah proyek.

3. Proyek ini direncakan memiliki 7 lantai basement.

4. Metode galian dalam pada proyek ini adalah metode top down. 
5. Dinding penahan tanah yang digunakan adalah diaphragm wall (dinding diafragma) dengan ketebalan 1 meter dan kedalaman 55 meter.

6. Analisis galian dalam akan terbagi pada 2 kondisi yaitu drained dan undrained.

7. Perhitungan dilakukan pada kondisi beban static, tidak memperhitungkan kondisi dynamic.

8. Pada analisis ini digunakan model kegagalan tanah Mohr-Coulomb.

9. Dilakukan analisis deformasi dan gaya momen pada diaphragm wall, serta gaya pada strut/slab menggunakan bantuan progam elemen hingga (2D).

10. Perubahan Muka Air Tanah tidak diperhitungkan.

11. Deformasi pada beton di dinding penahan tanah (dinding diafragma) tidak diperhitungkan.

\section{Rumusan Masalah}

Rumusan masalah yang akan dibahas adalah:

1. Berapa besar deformasi yang dapat terjadi pada diaphragm wall saat kondisi undrained dan drained jika ada 2 lantai yang dihilangkan sementara?

2. Berapa besar gaya momen yang terjadi sepanjang diaphragm wall saat kondisi undrained dan drained jika ada 2 lantai yang dihilangkan sementara?

3. Berapa besar gaya pada strut/slab yang terjadi jika ada 2 lantai yang dihilangkan sementara jika ada 2 lantai yang dihilangkan sementara?

4. Dimanakah ring slab/strut dapat dihilangkan sementara pada galian dalam tersebut agar efektif?

\section{Tujuan Penelitian}

Tujuan dari penelitian ini antara lain:

1. Mengetahui besar deformasi yang dapat terjadi pada diaphragm wall saat kondisi undrained dan drained jika ada 2 lantai yang dihilangkan sementara.

2. Mengetahui besar gaya momen yang terjadi pada sepanjang diaphragm wall saat kondisi undrained dan drained jika ada 2 lantai yang dihilangkan sementara.

3. Mengetahui besar gaya strut/slab yang terjadi jika ada 2 lantai yang secara efektif dihilangkan sementara.

4. Mengetahui posisi penghilangan ring slab/strut yang efektif pada galian dalam proyek.

\section{TINJAUAN PUSTAKA}

\section{Undrained Shear Strength of Soils}

Pada kondisi dimana shear strength memiliki kadar air dan volume pada suatu lempung yang konstan dan excess pore pressure dihasilkan maka kondisi ini disebut sebagai undrained shear strength. Jika lempung jenuh pada kondisi undrained dianalisis pada kondisi total, maka perhitungan tekanan air pori tidak diperlukan. Kondisi ini dimana $\phi=0$ merupakan metode yang digunakan untuk analisis undrained shear strength yang sama dengan nilai kohesi pada keruntuhan Coulomb untuk tegangan total (Terzaghi, 1996).

\section{Drained Shear Strength of Soils}

Bedasarkan effective stress principle, ketahanan maksimum geser pada tanah bukan merupakan fungsi dari tegangan normal, tetapi perbedaan antara tegangan normal dan tekanan air pori, seperti ketika tanah digali, volume tanah berubah yang akan menyebabkan perubahan tekanan air pori $\Delta u=0$. Untuk partially drained atau kondisi undrained, nilai dari $\Delta \mathrm{u}$ tergantung dari pembeban dibandingkan dengan drainase dalam tanah. Perubahan tekanan air pori, yang disebabkan oleh perubahan tegangan pada kondisi undrained (Terzaghi, 1996).

\section{Dinding Diafragma}

Dinding diafragma merupakan sebuah dinding penahan tanah dan juga digunakan sebagai dinding pada lantai basement. Dinding diafragma memiliki kekakuan yang sangat besar diantara dinding penahan tanah lainnya, getaran yang rendah saat pengerjaan, deformasi dinding kecil dan ketebalan serta kedalaman dinding diafragma dapat disesuaikan sehingga pada galian dalam sering digunakan. Dinding diafragma juga dapat disebut sebagai slurry walls.

\section{Tekanan Tanah Lateral}

Tekanan tanah lateral merupakan kondisi dimana adanya gaya horisontal yang bekerja pada tanah ke dinding penahan. Tekanan tanah lateral dapat disebabkan oleh massa tanah itu sendiri atau dari beban yang berada diatas tanah. Metode kesetimbangan plastis seperti yang dijelaskan dalam selubung keruntuhan mohr adalah metode yang biasa digunakan dalam memperkirakan tekanan lateral pada tanah (Bowles, 1991). Pada galian dalam, analisa gaya 
tekanan tanah lateral sangat dibutuhkan karena kesalahan pada perencanaan tekanan tanah lateral dapat menyebabkan desain tidak ekonomis dan tidak aman.

Tekanan tanah lateral terbagi atas 3 keadaan yaitu (Ou, 2006).:

1. Tekanan Tanah Pada Keadaan Diam

Tekanan tanah ini terjadi apabila tidak ada gesekan antara dinding penahan dan tanah. Pada kondisi ini dinding penahan dianggap sangat kaku dan pergerakan tidak diijinkan, sehingga keadaan tanah dibawah permukaan dapat disebut dalam keadaan keseimbangan elastis (elastic equilibrium) tanpa tegangan geser.

2. Tekanan Tanah Aktif

Tekanan tanah aktif merupakan tekanan tanah lateral yang terjadi pada bagian belakang dinding penahan, yang disebabkan apabila dinding penahan harus menahan longsornya tanah pada bagian belakang dinding penahan. Atau saat dinding bergerak menjauh dari tahan yang berada dibelakang. Tekanan tanah ini merupakan gaya yang dapat mengurangi keseimbangan dinding penahan tanah.

3. Tekanan Tanah Pasif

Tekanan tanah pasif merupakan tekanan tanah lateral yang terjadi pada bagian depan dinding penahan, saat suatu gaya mendorong dinding penahan ke arah belakang. Tekanan tanah pasif ini berusaha menahan tekanan aktif yang terjadi sehingga tekanan pasif merupakan tekanan tanah yang arahnya berlawanan dengan tekanan tanah aktif.

\section{METODOLOGI PENELITIAN}

\section{Metode Pengumpulan Data}

Metode yang digunakan dalam pengumpulan data-data yang akan dipakai adalah dengan pengumpulan data dari proyek. Pada studi ini, data tanah yang dianalisis berlokasi di kawasan Bendungan Hilir, DKI Jakarta. Data tanah berupa 13 drilling log, 24 data sondir, dan hasil tes laboratorium.

\section{Metode Analisis Data}

Analisis data pertama dilakukan dengan menganalisis data-data tanah yang tersedia dan dilakukan pengklasifikasian jenis tanah beserta lapisannya. Lalu dilakukan pencarian parameter-parameter yang dibutuhkan untuk diinput kedalam program elemen hingga (2D). Selain data-data tanah, dilakukan juga analisis terhadap parameter-parameter yang dibutuhkan pada dinding diafragma serta strut/slab. Sebelum melalukan analisis, dilakukan pembelajaran serta teori-teori dan studi yang berhubungan dengan topik penelitian kali ini. Dalam penelitian ini, digunakan peraturan SNI 8460:2017 sebagai acuan serta batasan-batasan dalam analisa ini.

\section{ANALISIS DAN PEMBAHASAN}

\section{Parameter Yang Digunakan}

Untuk memasukan data-data parameter yang dibutuhkan untuk input kedalam program elemen hingga (2D), maka sebelumnya diperlukan analisa parameter tanah serta korelasi-korelasi tanah yang dibutuhkan. Parameter tanah didapat dari data drilling log, data sondir serta data hasil uji laboratorium. Data tanah yang digunakan akan dibagi kedalam 2 kondisi yaitu kondisi drained dan undrained. Perbedaan parameter data tanah kondisi drained dan undrained terletak pada sudut geser dalam dan kohesi tanah.

Selain data-data parameter tanah, dibutuhkan juga data-data parameter dinding penahan tanah (dinding diafragma) serta data slab (strut). Pada data dinding penahan tanah, dibutuhkan nilai kekakuan normal dan kekakuan lentur, berat serta nilai poisson. Dan data strut yang dimasukan kedalam program elemen hingga (2D) adalah kekakuan normal.

Selanjutnya data-data ini dimasukan kedalam program elemen hingga (2D) dan dilakukan analisis pada kedua kondisi untuk 6 percobaan. Berikut ini rekap input parameter yang akan digunakan:

Tabel 1. Rekap Input Parameter Tanah Kondisi Drained

\begin{tabular}{cccccccccc}
\hline Parameter & Lapisan & Lapisan & Lapisan & Lapisan & Lapisan & Lapisan & Lapisan & Lapisan & Satuan \\
& 1 & 2 & 3 & 4 & 5 & 6 & 7 & 8 & \\
\hline$\gamma_{\text {unsat }}$ & 16 & 17.5 & 17.5 & 17.5 & 17.5 & 17.5 & 17.5 & 17.5 & $\mathrm{kN} / \mathrm{m}^{3}$ \\
\hline$\gamma_{\text {sat }}$ & 18 & 19 & 20 & 20 & 20 & 20 & 20 & 21 & $\mathrm{kN} / \mathrm{m}^{3}$ \\
\hline$k_{x} \& k_{y}$ & $8,64 \mathrm{x}$ & $8,64 \mathrm{x}$ & $8,64 \mathrm{x}$ & $8,64 \mathrm{x}$ & $8,64 \mathrm{x}$ & $8,64 \mathrm{x}$ & $8,64 \mathrm{x}$ & $8,64 \mathrm{x}$ & $\mathrm{m} / \mathrm{hari}$ \\
& $10^{-3}$ & $10^{-2}$ & $10^{-2}$ & $10^{-3}$ & $10^{-3}$ & $10^{-3}$ & $10^{-3}$ & $10^{-3}$ & \\
\hline
\end{tabular}




\begin{tabular}{cccccccccc}
\hline$E_{\text {ref }}$ & 21000 & 75000 & 63000 & 63000 & 90000 & 90000 & 82500 & 75000 & $\mathrm{kN} / \mathrm{m}^{2}$ \\
\hline$v$ & 0.35 & 0.25 & 0.25 & 0.3 & 0.3 & 0.3 & 0.3 & 0.3 & - \\
\hline$c_{\text {ref }}$ & 20 & 1 & 1 & 50 & 58 & 60 & 58 & 58 & $\mathrm{kN} / \mathrm{m}^{2}$ \\
\hline$\phi$ & 26 & 37 & 34 & 22 & 25 & 24 & 24 & 24 & $\circ$ \\
\hline$\Psi$ & 0 & 7 & 4 & 0 & 0 & 0 & 0 & 0 & $\circ$ \\
\hline$R_{\text {inter }}$ & 0.9 & 0.8 & 0.8 & 0.7 & 0.7 & 0.7 & 0.7 & 0.7 & -
\end{tabular}

Tabel 2. Rekap Input Parameter Tanah Kondisi Undrained

\begin{tabular}{cccccccccc}
\hline Parameter & Lapisan & Lapisan & Lapisan & Lapisan & Lapisan & Lapisan & Lapisan & Lapisan & Satuan \\
& 1 & 2 & 3 & 4 & 5 & 6 & 7 & 8 & \\
\hline$\gamma_{\text {unsat }}$ & 16 & 17.5 & 17.5 & 17.5 & 17.5 & 17.5 & 17.5 & 17.5 & $\mathrm{kN} / \mathrm{m}^{3}$ \\
\hline$\gamma_{\text {sat }}$ & 18 & 19 & 20 & 20 & 20 & 20 & 20 & 21 & $\mathrm{kN} / \mathrm{m}^{3}$ \\
\hline$k_{x} \& k_{y}$ & $8,64 \mathrm{x}$ & $8,64 \mathrm{x}$ & $8,64 \mathrm{x}$ & $8,64 \mathrm{x}$ & $8,64 \mathrm{x}$ & $8,64 \mathrm{x}$ & $8,64 \mathrm{x}$ & $8,64 \mathrm{x}$ & $\mathrm{m} / \mathrm{hari}$ \\
& $10^{-3}$ & $10^{-2}$ & $10^{-2}$ & $10^{-3}$ & $10^{-3}$ & $10^{-3}$ & $10^{-3}$ & $10^{-3}$ & \\
\hline$E_{\text {ref }}$ & 21000 & 75000 & 63000 & 63000 & 90000 & 90000 & 82500 & 75000 & $\mathrm{kN} / \mathrm{m}^{2}$ \\
\hline$v$ & 0.35 & 0.25 & 0.25 & 0.3 & 0.3 & 0.3 & 0.3 & 0.3 & - \\
\hline$c_{\text {ref }}$ & 70 & 1 & 1 & 210 & 300 & 300 & 275 & 250 & $\mathrm{kN} / \mathrm{m}^{2}$ \\
\hline$\phi$ & 0 & 37 & 34 & 0 & 0 & 0 & 0 & 0 & $\circ$ \\
\hline$\Psi$ & 0 & 7 & 4 & 0 & 0 & 0 & 0 & 0 & $\circ$ \\
\hline$R_{\text {inter }}$ & 0.9 & 0.8 & 0.8 & 0.7 & 0.7 & 0.7 & 0.7 & 0.7 & - \\
\hline
\end{tabular}

Tabel 3. Rekap Input Parameter Dinding Penahan Tanah

\begin{tabular}{cccc}
\hline Parameter & Nama & Nilai & Satuan \\
\hline Jenis perilaku & Jenis material & Elastis & - \\
\hline Kekakuan normal & EA & $2.5742 \times 10^{7}$ & $\mathrm{kN} / \mathrm{m}$ \\
\hline Kekakuan lentur & EI & $2.1452 \times 10^{6}$ & $\mathrm{kNm} / \mathrm{m}$ \\
\hline Tebal ekivalen & $d$ & 1 & $\mathrm{~m}$ \\
\hline Berat & $w$ & 24 & $\mathrm{kN} / \mathrm{m} / \mathrm{m}$ \\
\hline Angka poisson & $v$ & 0.15 & - \\
\hline
\end{tabular}

Tabel 4. Rekap Input Parameter strut (slab)

\begin{tabular}{cccc}
\hline Parameter & Nama & Nilai & Satuan \\
\hline Jenis perilaku & Jenis material & Elastis & - \\
\hline Kekakuan normal & EA & $2.5157 \times 10^{5}$ & $\mathrm{kN}$ \\
\hline Spasi keluar bidang gambar & $L_{s}$ & 1 & $\mathrm{~m}$ \\
\hline \multirow{2}{*}{ Gaya maksimum } & $F_{\text {maks,tekan }}$ & $1.10^{15}$ & $\mathrm{kN}$ \\
\cline { 2 - 4 } & $F_{\text {maks,tarik }}$ & $1.10^{15}$ & $\mathrm{kN}$ \\
\hline
\end{tabular}


Setelah dilakukan analisis pada program elemen hingga (2D), didapat nilai deformasi dinding diafragma kondisi drained dan undrained pada tiap percobaan, faktor keamanan pada tiap galian, nilai momen sepanjang tiang pada kondisi drained dan undrained serta gaya strut yang terjadi pada tiap galian. Setelah dilakukan perbandingan pada analisis deformasi dinding diafragma. Didapatkan bahwa nilai deformasi dinding diafragma pada kondisi drained pada 6 percobaan relatif lebih besar dibandingkan kondisi undrained. Oleh karena itu selanjutnya dilakukan perbandingan deformasi pada kondisi drained di keenam percobaan. Grafik perbandingan seperti berikut ini:

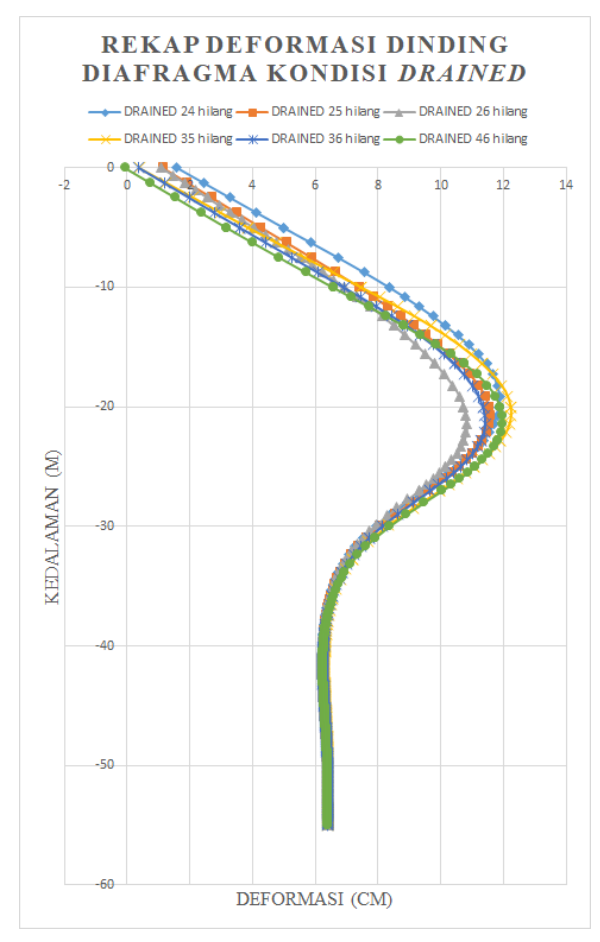

Gambar 1. Rekap Deformasi Dinding Diafragma Kondisi Drained

Didapatkan deformasi terkecil terjadi saat penghilangan lantai B2-B6 dihilangkan secara sementara yaitu deformasi maksimal adalah $10.826 \mathrm{~cm}$ sebagai opsi pertama penghilangan. Lalu deformasi kedua terkecil saat penghilangan lantai B3-B6 dihilangkan secara sementara yaitu deformasi maksimal adalah $11.423 \mathrm{~cm}$. Selanjutnya dilakukan perbandingan nilai momen sepanjang dinding diafragma saat kondisi drained. Grafik perbandingan seperti berikut ini: 


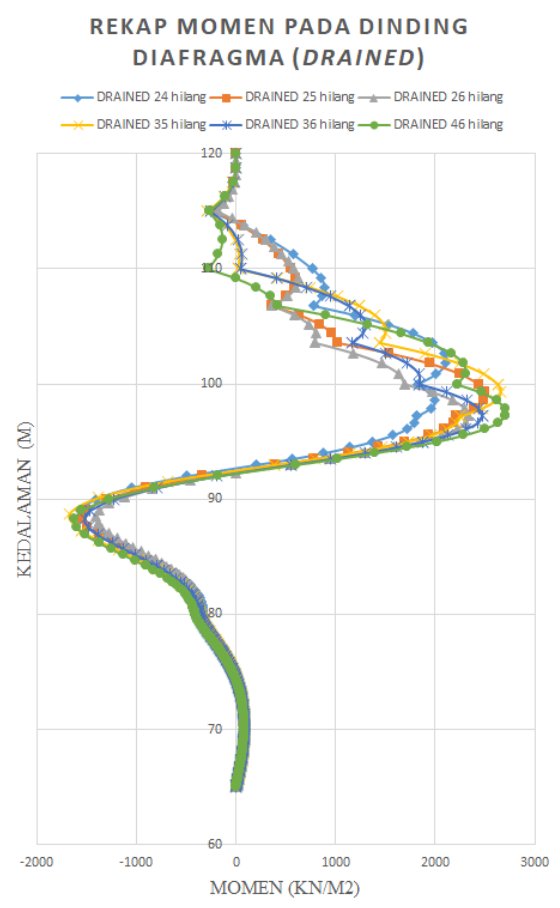

Gambar 2. Rekap Momen Pada Dinding Diafragma (Drained)

Dari grafik diatas didapat bahwa penghilangan slab pada lantai B2 dan B4 memiliki nilai momen positif sepanjang tiang yang terkecil, relatif sama, tidak terlalu mencolok. Kemudian pada penghilangan slab di lantai B2 dan B6, momen yang terjadi pada dinding merupakan momen kedua terkecil pada dinding setelah penghilangan slab pada lantai B2 dan B4.

Setelah dilakukan perbandingan nilai deformasi dan nilai momen pada dinding diafragma, selanjutnya dilakukan pebandingan nilai gaya pada strut/slab pada tiap tahap galian. Lalu dicari yang paling minimum, berikut ini adalah grafik-grafik nilai gaya strut dari B1 hingga B6:

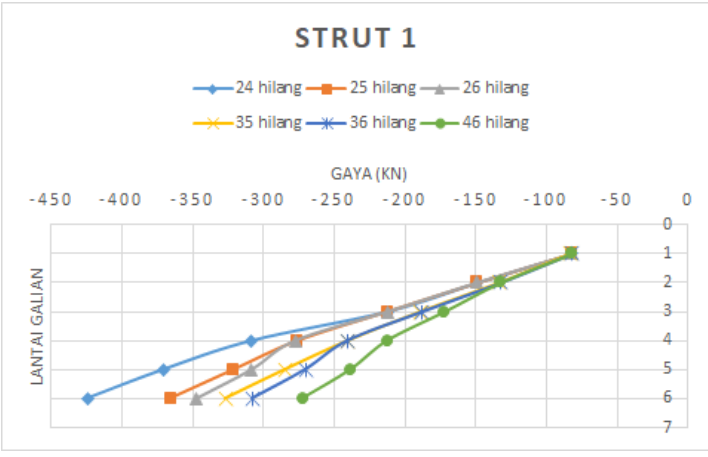

Gambar 3. Gaya Yang Terjadi Pada Strut 1

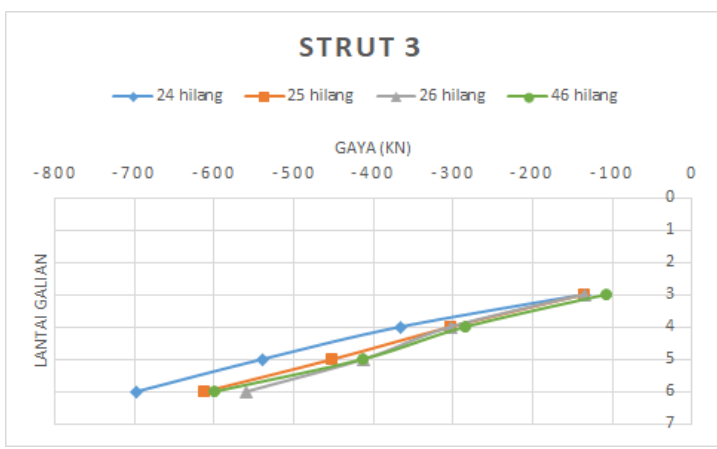

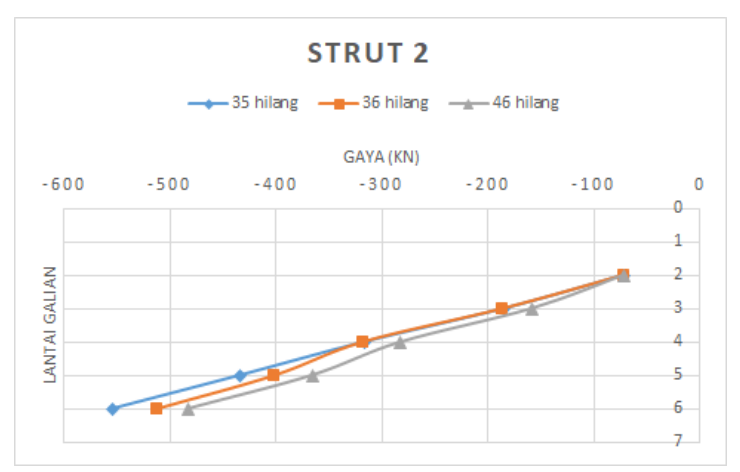

Gambar 4. Gaya Yang Terjadi Pada Strut 2

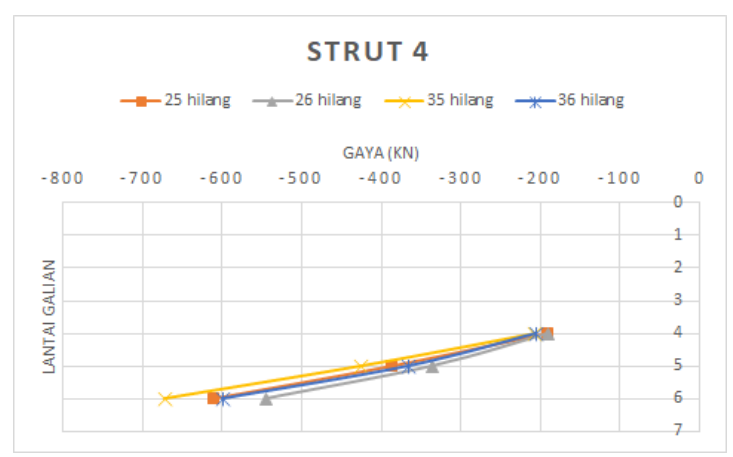




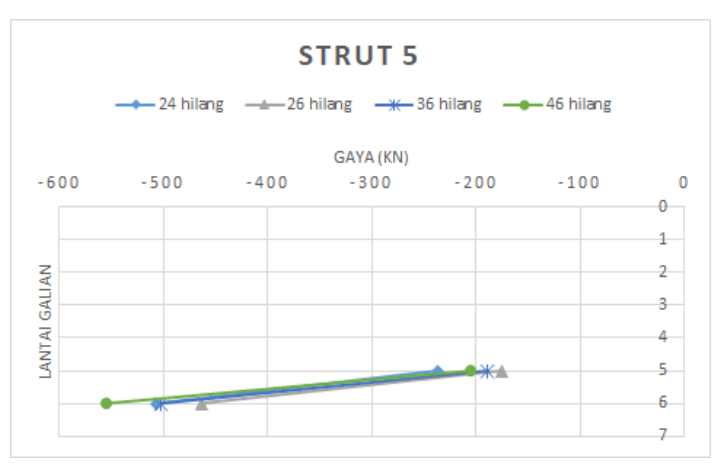

Gambar 7. Gaya Yang Terjadi Pada Strut 5

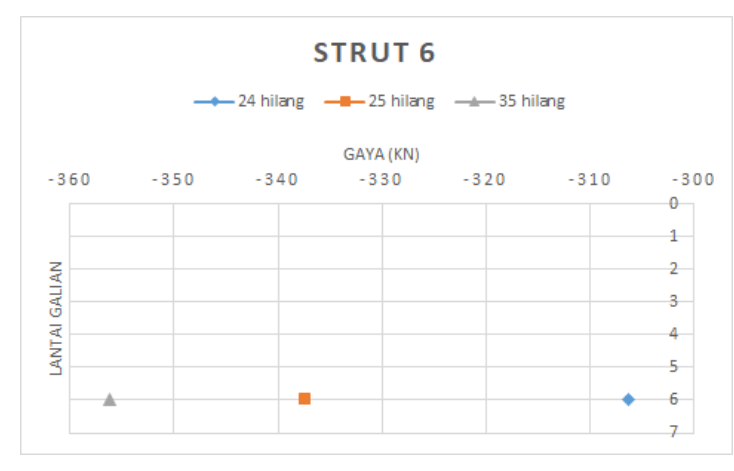

Gambar 8. Gaya Yang Terjadi Pada Strut 6

Dari grafik gaya strut pada tiap lantai diatas, maka dibuat rekap data untuk setiap strut. Rekap data diurutkan bedasarkan nilai gaya strut dari yang terkecil hingga terbesar pada tiap strut/slab.

Tabel 4.5 Tabel Urutan Gaya Strut Dari Terkecil-Terbesar

\begin{tabular}{ccccccc}
\hline Keterangan & $\begin{array}{c}\text { Strut 1 } \\
\mathbf{( 4 5 0 k N )}\end{array}$ & $\begin{array}{c}\text { Strut 2 } \\
\mathbf{( 6 0 0 k N )}\end{array}$ & $\begin{array}{c}\text { Strut 3 } \\
(\mathbf{6 0 0 k N )}\end{array}$ & $\begin{array}{c}\text { Strut 4 } \\
\mathbf{( 8 0 0 k N )}\end{array}$ & $\begin{array}{c}\text { Strut 5 } \\
(\mathbf{6 0 0 k N )}\end{array}$ & $\begin{array}{c}\text { Strut 6 } \\
\mathbf{( 3 6 0 k N )}\end{array}$ \\
\cline { 2 - 7 } & 46 & 46 & 26 & 26 & 26 & 24 \\
\cline { 2 - 7 } $\begin{array}{c}\text { Gaya } \\
\text { Terkecil - } \\
\text { Terbesar }\end{array}$ & 36 & 36 & 46 & 36 & 36 & 25 \\
\cline { 2 - 7 } & 26 & 35 & 25 & 25 & 24 & 35 \\
\cline { 2 - 7 } & 25 & 24 & 35 & 46 & \\
\cline { 2 - 7 } & 24 & & & & \\
\end{tabular}

Dari tabel diatas, gaya pada strut B2, strut B3, strut B4 dan strut B5 memiliki gaya yang paling besar, maka diambil nilai dari strut/slab tersebut. Karena 3 dari 4 strut menunjukan bahwa gaya terkecil terjadi jika strut B2 dan strut B6 yang dihilangkan. Maka analisis perbandingan bedasarkan besarnya gaya strut, akan dipilih B2 dan B6 yang tidak dicor sementara.

\section{KESIMPULAN}

Berdasarkan analisis yang dilakukan, didapatkan beberapa kesimpulan sebagai berikut:

1. Analisis pada program elemen hingga menunjukan bahwa pada kondisi drained memiliki angka keamanan yang relatif lebih kecil dibandingkan dengan kondisi undrained. Hal ini menunjukan bahwa pada kondisi drained tanah memiliki permeabilitas tinggi sehingga air dapat dengan mudah mengalir.

2. Hasil nilai deformasi dinding diafragma pada keenam percobaan menunjukan bahwa, deformasi maksimal terjadi pada kondisi drained. Sehingga analisis selanjutnya dilakukan dengan melakukan perbandingan deformasi pada kondisi drained.

3. Pada analisis dari perbandingan keenam percobaan pada kondisi drained, didapatkan deformasi dinding terkecil terjadi saat lantai B2 dan lantai B6 dicor terakhir yaitu $10.8 \mathrm{~cm}$.

4. Pada perbandingan gaya momen yang terjadi pada keenam percobaan, didapat bahwa jika pada lantai B2 dan lantai B4 dihilangkan sementara maka akan menghasilkan nilai momen terkecil dan nilai yang tidak jauh berbeda sepanjang dinding. Sedangkan jika dihilangkan pada lantai B2 dan lantai B6 akan menghasilkan nilai momen kedua terkecil.

5. Pada perbandingan gaya strut yang terjadi untuk tiap tahap galian, didapat bahwa jika lantai B2 dan lantai B6 yang dihilangkan sementara, maka gaya-gaya yang terjadi pada strut /lantai lain adalah yang paling minimal.

6. Dari kesimpulan diatas, penulis memutuskan untuk menghilangkan lantai B2 dan B6 sementara untuk proyek galian dalam ini. 


\section{KONSTRUKSI BASEMENT}

\section{DAFTAR PUSTAKA}

Bowless, J.E. (1991). Analisis dan Desain Pondasi Jilid 1 Edisi Keempat. Jakarta: Penerbit Erlangga. Bowless, J.E. (1991). Analisis dan Desain Pondasi Jilid 2 Edisi Keempat. Jakarta: Penerbit Erlangga. Chang-Yu Ou (2006). Deep Excavation Theory and Practice. Netherlands: Taylor \& Francis Group.

Terzaghi, K., Peck, R.B. and Mesri, G. (1996). Soil Mechanics in Engineering Practice Third Edition. New York: John Wiley \& Sons, Inc. 